\title{
Mass spectrometry-based assay for the molecular diagnosis of glioma: concomitant detection of chromosome 1p/19q codeletion, and IDH1, IDH2, and TERT mutation status
}

\author{
Chiara Pesenti ${ }^{1,2}$, Leda Paganini ${ }^{1,2}$, Laura Fontana ${ }^{1}$, Emanuela Veniani ${ }^{2}$, Letterio \\ Runza $^{2}$, Stefano Ferrero ${ }^{2,3}$, Silvano Bosari ${ }^{1,2}$, Maura Menghi ${ }^{4}$, Giovanni Marfia ${ }^{5,6}$, \\ Manuela Caroli', Rosamaria Silipigni, Silvana Guerneri7, Silvia Tabano ${ }^{1}$ and \\ Monica Miozzo', \\ ${ }^{1}$ Department of Pathophysiology and Transplantation, Università degli Studi di Milano, Milan, Italy \\ ${ }^{2}$ Division of Pathology, Fondazione IRCCS Ca' Granda Ospedale Maggiore Policlinico, Milan, Italy \\ ${ }^{3}$ Department of Biomedical, Surgical and Dental Sciences, Università degli Studi di Milano, Milan, Italy \\ ${ }^{4}$ Diatech Pharmacogenetics, Jesi, Italy \\ ${ }^{5}$ Laboratory of Experimental Neurosurgery and Cell Therapy, Neurosurgery Unit, Fondazione IRCCS Ca' Granda, Ospedale \\ Maggiore Policlinico, Milan, Italy \\ ${ }^{6}$ Neurosurgery Unit, Fondazione IRCCS Ca' Granda, Ospedale Maggiore Policlinico, Milan, Italy \\ ${ }^{7}$ Laboratory of Medical Genetics, Fondazione IRCCS Ca' Granda Ospedale Maggiore Policlinico, Milan, Italy
}

Correspondence to: Silvia Tabano, email: silvia.tabano@unimi.it

Keywords: glioma, 1p/19q LOH, massARRAY, IDH, TERT

Received: March 13, 2017 Accepted: June 19, $2017 \quad$ Published: July 08, 2017

Copyright: Pesenti et al. This is an open-access article distributed under the terms of the Creative Commons Attribution License 3.0 (CC BY 3.0), which permits unrestricted use, distribution, and reproduction in any medium, provided the original author and source are credited.

\section{ABSTRACT}

The World Health Organization recently revised the diagnosis of glioma, to integrate molecular parameters, including IDH mutations and codeletion (loss of heterozygosity; LOH) of chromosome arms 1p/19q, into the definitions of adult glioma histological subtypes. Mutations in the TERT promoter may also be useful for glioma diagnosis and prognosis. The integration of molecular markers into routine diagnosis requires their rapid and reliable assessment. We propose a MassARRAY (MS)-based test that can identify 1p/19q codeletion using quantitative SNP genotyping and, simultaneously, characterize hotspot mutations in the IDH1, IDH2, and TERT genes in tumor DNA. We determined the reliability of the MS approach testing $\mathbf{5 0}$ gliomas and comparing the MS results with those obtained by standard methods, such as short tandem repeat genotyping, array comparative genomic hybridization (array-CGH) and Fluorescence In Situ Hybridization (FISH) for 1p/19q codeletion and Sanger sequencing for hotspots mutations. The results indicate that MS is suitable for the accurate, rapid, and cost-effective evaluation of chromosome deletions combined with hotspot mutation detection. This MS approach could be similarly exploited in evaluation of LOH in other situations of clinical and/or research importance.

\section{INTRODUCTION}

Diffuse gliomas are the most common brain tumor, accounting for $27 \%$ of all brain neoplasms and $80 \%$ of malignant tumors [1]. Until last year, diffuse gliomas were classified on the basis of histological criteria and 2007 World Health Organization (WHO) grading
[2]. The increasing and extensive characterization of the genomic landscape of gliomas prompted the identification of genetic and epigenetic markers useful for tumor molecular classification; in the future, these molecular signatures could also represent actionable targets in gliomas, as is already the case for other cancers $[3-5]$. 
At the beginning of 2016, the WHO Classification of Tumors of the Central Nervous System (CNS) (2016 CNS WHO) revised the diagnostic guidelines for gliomas, to include molecular markers and create a novel concept of diagnosis, termed "integrated" diagnosis, characterized by the concomitant evaluation of phenotypic and genotypic parameters [6]. This new integrated diagnostic process not only aims to achieve greater objectivity, but also to improve patient management. The 2016 CNS WHO criteria state that, for a complete diagnosis of the types of adult glioma, analysis for specific mutations of the two genes, IDH1 and IDH2 (IDH), which encode isocitrate dehydrogenase 1 and 2, respectively, and of chromosome $1 \mathrm{p} / 19 \mathrm{q}$ codeletion status, is essential.

Mutations of IDH1 (codon 132) or IDH2 (codon 172) allow discrimination between two classes of glioblastoma (GBM), IDH-wildtype and IDH-mutant, with differing genomic and epigenomic landscapes and prognoses $[5,7,8]$. Moreover, IDH mutations are almost invariably present in low grade gliomas (LGGs), including oligodendroglioma (ODG) and astrocytoma (AC) [7, 9]. IDH mutations are an early event in glioma tumorigenesis [5], and several mechanisms have been proposed to explain their role in neoplastic transformation. Mutant IDH enzymes acquire neomorphic activity and produce an oncometabolite, 2-HG, which is able to modify the epigenetic profile of cells, leading to the establishment of the $\mathrm{CpG}$ island methylator phenotype (G-CIMP). The production of 2-HG stimulates cell proliferation by reducing levels of the hypoxia-inducible factors. Moreover, IDH mutations promote tumorigenesis by decreasing intracellular levels of NADPH, which also has the effect of increasing the sensitivity of tumor cells to cytotoxic therapies, accounting for the positive prognostic value of this marker (see [10] for a review).

Once the IDH mutation status has been defined, the histological type of LGGs can be determined by evaluation of $1 \mathrm{p} / 19 \mathrm{q}$ status. Codeletion of the chromosome arms $1 p$ and $19 q(1 p / 19 q$ loss of heterozygosity; LOH) is the result of the unbalanced translocation $[\mathrm{t}(1 ; 19)(\mathrm{q} 10 ; \mathrm{p} 10)]$ and enables discrimination between ODG and AC. Both of these LGGs are characterized by IDH mutations; however, only ODGs exhibit $1 \mathrm{p} / 19 \mathrm{q}$ codeletion $[6,9]$. Furthermore, the presence of $1 \mathrm{p} / 19 \mathrm{q} \mathrm{LOH}$ in ODGs is positively correlated with sensitivity to radiotherapy and chemotherapy using alkylating agents [11].

In addition to IDH and $1 \mathrm{p} / 19 \mathrm{q}$ status, two mutations in the promoter region of the telomerase reverse transcriptase (TERT) gene are frequently identified in various types of cancer $[12,13]$, including glioma $[14,15]$. These single nucleotide substitutions occur in a mutually exclusive manner in two hotspot positions upstream of the ATG start site: c. $-124 \mathrm{G}>\mathrm{A}$ and c. $-146 \mathrm{G}>\mathrm{A}$ (also termed $\mathrm{C} 228 \mathrm{~T}$ and $\mathrm{C} 250 \mathrm{~T}$, respectively). The mutations generate a consensus binding site for the E-twenty-six transcription factor, which upregulates TERT expression and thus induces the maintenance of telomere length and tumor proliferation [16-19].

TERT promoter mutations are found in more than $70 \%$ of GBMs, in particular in the IDH-wildtype subgroup, and in almost all ODGs (nearly 95\%) [6]. These mutations occur less frequently in ACs, which usually have mutations in the alpha thalassemia/mental retardation syndrome $\mathrm{X}$-linked (ATRX) gene, another locus involved in telomere lengthening [20]. The presence of TERT mutations is also important for glioma prognosis, since gliomas (in particular LGGs) with concomitant IDH and TERT mutations are associated with better prognosis, while patients with IDH-wildtype and TERT mutated GBMs have poorer prognoses.

The absence of $M G M T$ promoter methylation is an additional negative prognostic factor in TERT mutated GBM [8, 15, 21-24], and assessment of $M G M T$ promoter methylation status assists in better defining prognosis for patients with gliomas, due to the role of this feature as a predictive marker of therapeutic efficacy [25].

Figure 1 summarizes the molecular diagnostic flowchart proposed by the 2016 CNS WHO, comprising analysis of the markers described above, and suggests the evaluation of additional genes, including ATRX and TP53 mutations [4, 20], for profiling of ACs, TERT mutations for ODGs and GBMs, and $M G M T$ promoter methylation for GBMs.

Together, these molecular markers allow the stratification of glioma patients in terms of prognosis and response to treatments [20, 26, 27], highlighting the importance of early molecular profiling of gliomas for a more precise patient management.

The presence of $1 \mathrm{p} / 19 \mathrm{q} \mathrm{LOH}$ is routinely assessed by FISH or genotyping of short tandem repeats (STRs), while IDH and TERT mutations are usually investigated by sequencing or real-time PCR. The use of multiple techniques for diagnostic purposes is laborious and timeconsuming. Conversely, next generation sequencing (NGS) approaches [28-30] allow the simultaneous detection of markers; however, the technique is very expensive for use in medium-sized laboratories where, in general, only a few cases will be analyzed simultaneously. To overcome these limitations, we propose the MS system as a feasible high-throughput technology to simultaneously define the presence of $1 \mathrm{p} / 19 \mathrm{q} \mathrm{LOH}$ and hotspot mutations in IDH1, IDH2, and TERT.

MS technology uses a matrix-assisted laser desorption ionization time-of-flight (MALDI-TOF) massspectrometry platform to perform multiplex genotyping with high accuracy, even where only small amounts of poor-quality template material, such as DNA obtained from formalin-fixed paraffin-embedded (FFPE) tissue samples, are available [31]. The technique has already been introduced for routine diagnostics as a fast, reliable, and cost-effective approach, with specific CE marked in vitro diagnostic tests in Europe for the molecular 
characterization of colon and lung cancer [32]. Two previous reports $[33,34]$ investigated colon and lung cancers and demonstrated that MS can be exploited for the identification of chromosome deletions. In particular, van Puijgenbroek et al. [33] analyzed only one SNP in colon cancers and Tai et al. [34] evaluated a panel of SNPs, but without a quantitative approach to define the presence/ absence of the deletions. Nevertheless, deletion analysis by MS has not been previously applied in molecular diagnosis of cancers, and $\mathrm{CE}$ marked in vitro diagnostic tests using this method are not currently available to analyze $\mathrm{LOH}$, either alone or together with cancer hotspot mutations.

To develop an accurate test for $1 \mathrm{p} / 19 \mathrm{q} \mathrm{LOH}$ by MS, we quantitatively genotyped a panel of highly polymorphic biallelic single nucleotide polymorphisms (SNPs) evenly distributed along chromosomes $1 \mathrm{p}$ and 19q. We applied the proposed technique to 50 gliomas and compared the results of MS for $1 \mathrm{p} / 19 \mathrm{q} \mathrm{LOH}$ with those obtained by the standard methods, STR genotyping, array-CGH and FISH. In addition, we genotyped by MS IDH1 codon 132, IDH2 codon 172 , TERT c. $-124 \mathrm{C}>\mathrm{T}$ and c. $-146 \mathrm{C}>\mathrm{T}$ promoter mutations, validating the results by Sanger sequencing.
The results described here demonstrate that the MS test accurately combines the evaluation of IDH and TERT mutations with that of $1 \mathrm{p} / 19 \mathrm{q} \mathrm{LOH}$, in accordance with the recent WHO guidelines.

\section{RESULTS}

\section{MS assay optimization for molecular diagnosis of gliomas}

The MS assay optimized in our laboratory is able to reveal $\mathrm{LOH}$ at $1 \mathrm{p} / 19 \mathrm{q}$ chromosome arms and the presence of hotspot mutations in IDH1,IDH2, and TERT. It was optimized and validated by the analysis of 50 glioma samples, as detailed below.

For $1 \mathrm{p} / 19 \mathrm{q}$ LOH analysis, we applied specific criteria to define SNPs as heterozygous and a formula to assess LOH, as detailed in Materials and Methods. An example of a sample with $\mathrm{LOH}$, in which one of the two alleles detected in blood DNA was lost in the corresponding tumor DNA, thus significantly modifying the allele frequencies and resulting in a value of 0.9 using our formula, is presented in Figure 2A. An example of
Diffuse glioma WHO II and III, LGGs

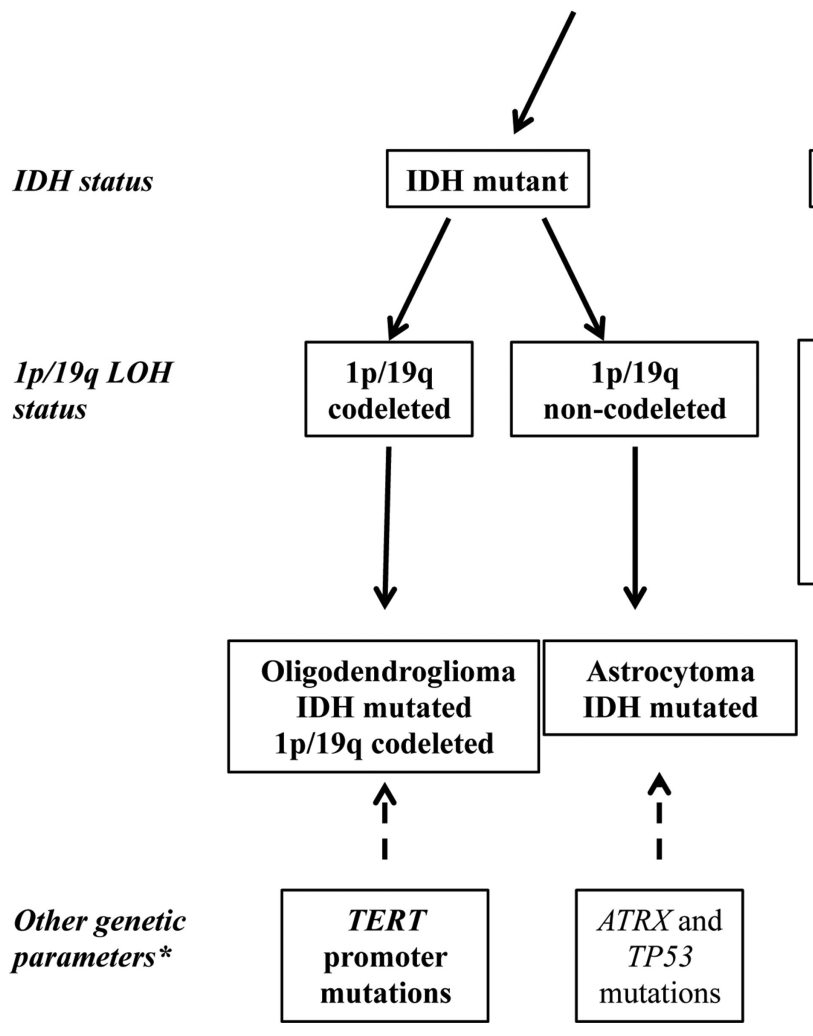

Diffuse glioma WHO IV, HGGs
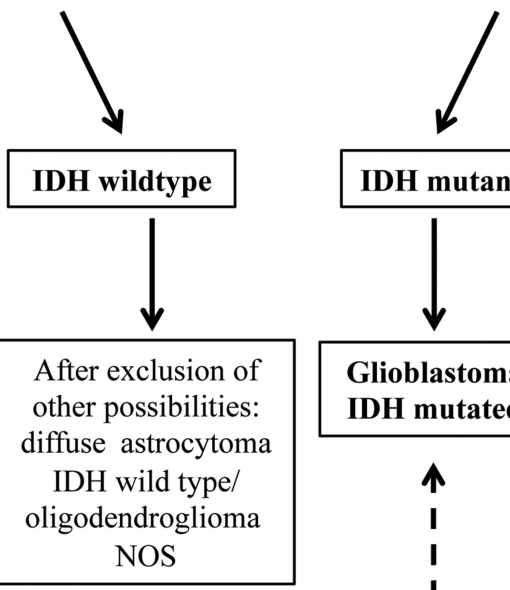

IDH mutant

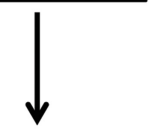

Glioblastoma

IDH mutated

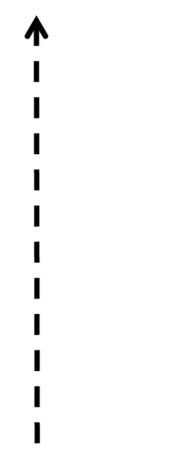

TERT promoter mutations

$M G M T$ promoter methylation

Figure 1: Simplified flowchart for the molecular characterization of diffuse gliomas (adapted from 2016 CNS WHO [5]). The detection of IDH mutations allows the distinction between primary and secondary GBM in HGGs and is necessary to discriminate between the LGGs, astrocytoma, and oligodendroglioma. LGGs with wildtype IDH are very rarely observed and, after the exclusion of other possible diagnoses, should be classified as NOS (not otherwise specified). The analysis of 1p/19q LOH is necessary to distinguish between oligodendroglioma and astrocytoma. *Other genetic markers characteristic of each type of glioma, not yet required for diagnosis, but useful for the molecular characterization of glioma (i.e., TERT, TP53, and ATRX mutations, and MGMT methylation). 
a sample with no $\mathrm{LOH}$, in which the allele signals and frequencies from peripheral blood lymphocyte (PBL) and tumor DNA were similar and the value calculated using the formula was 0.50 (i.e., within the range defined as no imbalance; $>0.3<0.7$ ), is shown in Figure $2 \mathrm{~B}$.

$\mathrm{LOH} / \mathrm{NO}$ LOH status was defined by the presence of at least two informative SNPs per chromosome arm with concordant results, one of which was located in a centromeric region and the other at a telomeric locus. Overall, we found that the average number of informative SNPs per sample was about six for both chromosome regions. As detailed in Table 1, more than two informative SNPs were available in all cases, with the exception of cases n. 29 and 36, showing only two informative SNPs on $19 \mathrm{q}$ chromosome arm. As reported in Supplementary Table
1, heterozygous/informative SNPs were evenly distributed along the chromosome arms for each sample, enabling discrimination between whole or partial chromosome arm deletions. We did not identify any partial deletions of $1 p$ and/or $19 q$ in the analyzed population, although the MS test has the potential to detect such changes.

Applying the diagnostic flowchart proposed in Figure 1, the molecular characterization by MS supported the histological diagnosis. Indeed, $1 \mathrm{p} / 19 \mathrm{q} \mathrm{LOH}$ is a typical feature of ODG and anaplastic ODG and, in our population, all 16 ODG samples (Table 1, cases n. 1-16) resulted positive for $1 \mathrm{p} / 19 \mathrm{q}$ codeletion by MS. Conversely, all samples from tumors with other histotypes (AC and GBM) did not exhibit 1p/19q LOH or partial deletions of these chromosome arms (Table 1 and Figure 3).
A
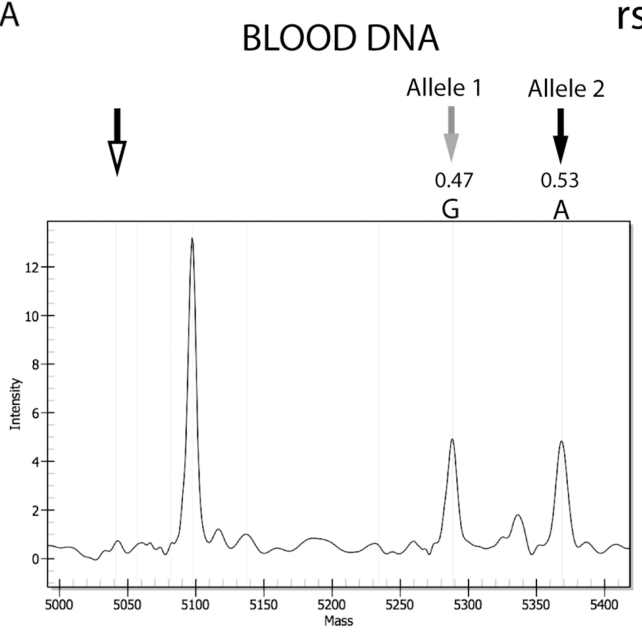

$\mathrm{B}$
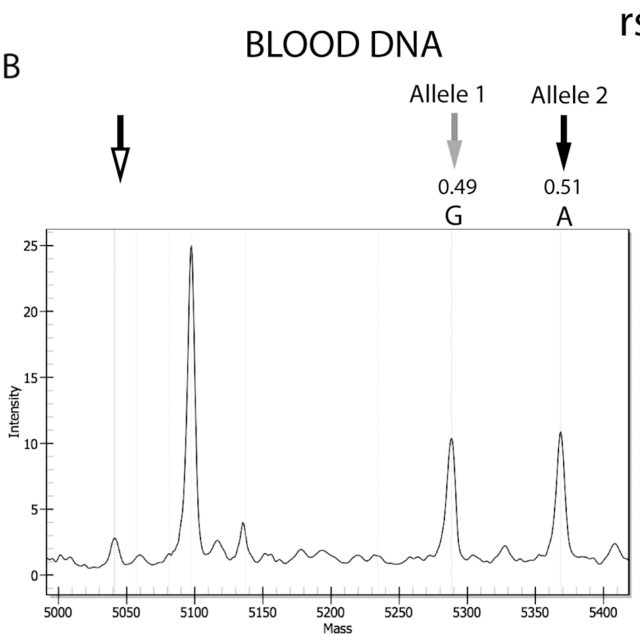

rs11247639

\section{TUMOR DNA}

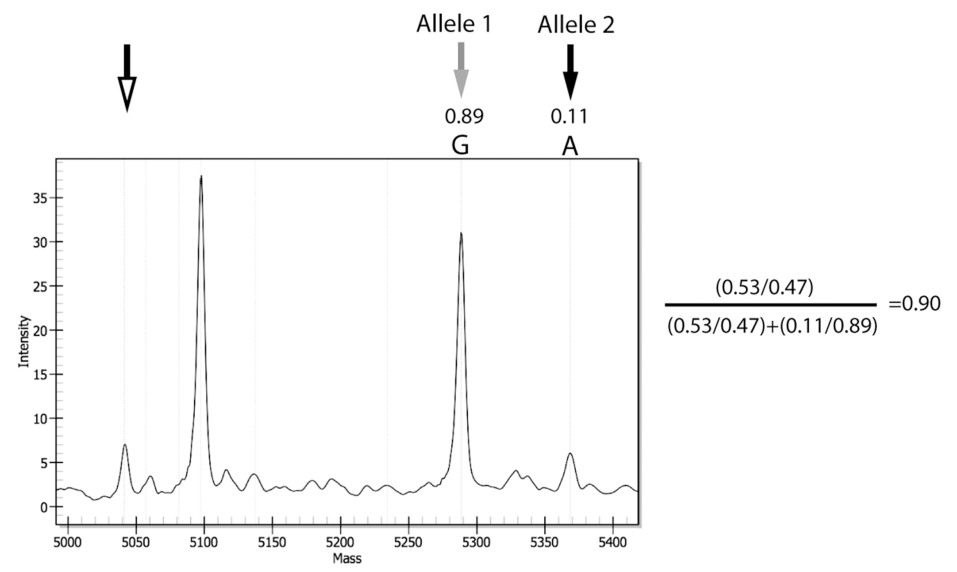

rs11247639

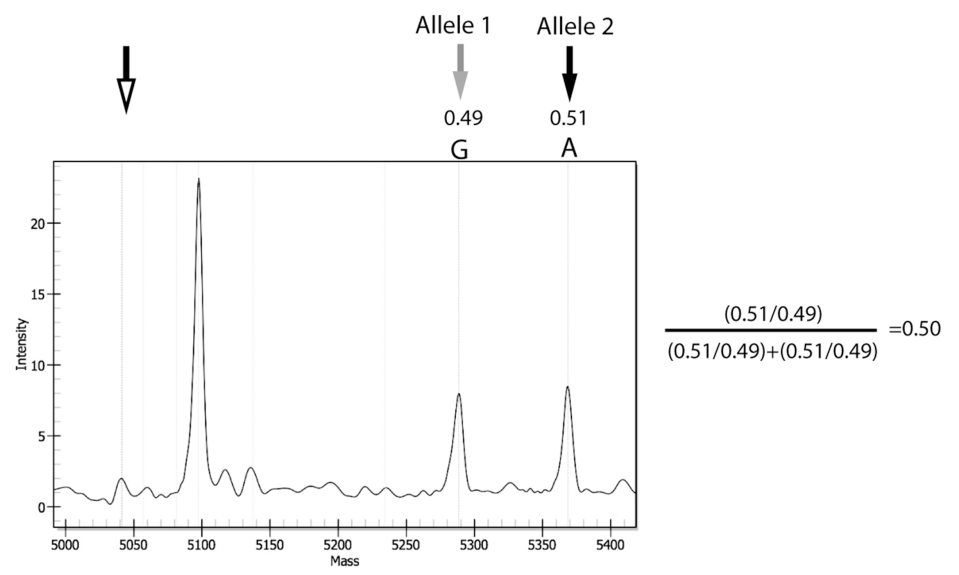

Figure 2: Example of results from gliomas with and without $1 \mathbf{p} / \mathbf{1 9 q}$ codeletion. Comparison between the allele signals from the informative SNP, rs11247639, from blood and tumor DNA from sample 10 and 28. (A) Spectra from a sample positive for LOH. Tumor DNA shows evident reduction of the allele 2 signal, compared with blood DNA. (B) Spectra from a sample negative for LOH. No relevant differences were observed in allele frequencies between blood and tumor DNA. Black and gray arrows indicate the Allele 1 and 2 peaks, respectively, while the unfilled arrows indicate the positions of the extension primers. Allele frequencies calculated by the MS software are shown, and the application of the formula confirming the presence or absence of LOH is presented to the right of the plots. The other peak present in the spectra represents the allele signal of another SNP of the MS test. The results from other informative SNPs in samples 10 and 28 were concordant with those from rs 11247639 and confirmed the presence of codeletion in case 10 and its absence in case 28. 
As recommended by the 2016 CNS WHO [6], we also analyzed samples for mutations at codons 132 and 172 of $I D H 1$ and $I D H 2$, respectively. In the MS panel, 24 out of 50 tumors contained one of these mutations. The most frequent mutation, found in 20 tumors (13/16 ODGs, 6/8 ACs, 1/26 GBMs), was IDH1 c.395G >A (IDH1 R132H), in accordance with published data [7]; one ODG and one AC carried IDH1 c.394C > T (IDH1 R132C) mutations, one ODG IDH2 c.514A > T (IDH2 R172W), and one ODG IDH2 c.515G $>$ A (IDH2 R172K) (Table 1). The frequencies of the wildtype and mutated alleles generated using MS were always close to 0.5 , implying that 1 ) the mutations were present in almost all analyzed cells; 2) the tumor cell content was close to $100 \%$; and 3 ) the tumors were heterozygous for the mutations, in agreement with published data [5]. In particular, the average frequency of the $I D H 1$ allele encoding the $\mathrm{R} 132 \mathrm{H}$ mutation was $0.52 \%$ $\pm 3 \%$ (data not shown). Figure $4 \mathrm{~A}$ shows a representative spectrum from a mutated sample.

Finally, mutations in TERT promoter were found in 38 out of 50 samples. Thirty samples (13/16 ODGs, 17/26 GBMs) carried the c. $-124 \mathrm{C}>\mathrm{T}$ (TERT G228A) mutation and eight (three ODGs and five GBMs) the c.146C $>$ T (TERT G250A) mutation (Table 1), supporting the predominance of the G228A mutation in glioma [15]. Similar to the results of IDH gene analysis, the mutated allele of TERT was also highly represented (mean frequency: $0.59 \pm 0.15$ ); however, the high values of the standard deviation found among samples did not allow a precise quantification of the mutated allele, probably due to bias in the TERT amplification reaction. This could be caused by the high enrichment for $\mathrm{G} / \mathrm{C}$ nucleotides in this promoter region, that prevents an optimal DNA amplification, as already suggested by another report [29]. This issue was not observed with any of the other assays performed in this study. Figure 4B illustrates representative results from TERT mutated samples.

Given the histological diagnoses of the analyzed samples, the results of our molecular analysis are in line with published reports [6]. Indeed, all ODGs were positive for both IDH and TERT mutations, seven out of eight ACs were IDH-mutant (cases n.18-24), and no AC samples had mutations in TERT. Finally, the IDH1 R132H mutation was found in only one out of 26 GBM samples (case $n$ 32 ); conversely, the TERT mutations, which are frequent in GBM, were highly represented in our cases (22 out of 26 GBMs) (Figure 3).

\section{MS test validation}

To validate the results of the analysis by MS (Table 1), we compared them with those obtained using reference methods. To test $1 \mathrm{p} / 19 \mathrm{q} \mathrm{LOH}$, all 50 tumors were investigated by STR genotyping. The results obtained by this approach are detailed in Supplementary Figure 1A and are completely consistent with those from
MS assay. Ten cases were also analyzed by FISH (cases n. 1, 2, 4, 5 and 7 positive and n. 24, 25, 26, 28 and 30, negative for $1 \mathrm{p} / 19 \mathrm{q}$ LOH by MS, respectively). The FISH results are reported in Supplementary Figure 1B and FISH images, representative of $1 \mathrm{p} / 19 \mathrm{q}$ codeletion and noncodeletion status, are depicted in Supplementary Figure 1C. FISH analyses unequivocally confirmed the MS results. Nevertheless, commercial FISH probes, commonly used to analyze $1 \mathrm{p} / 19 \mathrm{q}$ codeletion, label only the telomeric portion of the $1 \mathrm{p}$ and $19 \mathrm{q}$; on the contrary, the MS assay allows a fine mapping of chromosome deletions because it exploits a SNPs panel entirely covering $1 p$ and $19 q$.

To further verify the efficiency of the MS test, four samples (samples nr 9 and 12, positive for $\mathrm{LOH}$, and nr 29 and 37 , negative for $\mathrm{LOH}$ ) were analyzed by array-CGH. The results were concordant with those of MS, confirming once more that the MS test correctly detects the codeletion of the whole chromosome $1 \mathrm{p}$ and $19 \mathrm{q}$ arms.

Finally, Sanger sequencing was exploited to verify the hotspot mutations in IDH1,IDH2 and TERT identified by MS. The sequencing analysis confirmed the results obtained by MS assay in all the investigated cases (marked by an asterisk in Table 1). Figures 4C and 4D displays the electropherograms of the respective MS spectra of two tumors (cases n. 4 and 37) with IDH1 R132H (Figure 4A) and TERT G228A (Figure 4B).

\section{DISCUSSION}

The revision of the WHO classification of brain tumors integrated molecular with histological parameters for their diagnosis and made the analysis of genetic markers mandatory. Using MS technology, we propose a novel, reliable, and cost-effective test that combines analyses of the diagnostic markers $1 \mathrm{p} / 19 \mathrm{q} \mathrm{LOH}$ and IDH mutations, required by the 2016 CNS WHO, together with the detection of TERT promoter mutations, relevant to patient prognosis.

The $1 p / 19 q$ LOH assay described in this paper genotypes 27 biallelic SNPs, carefully selected based on their frequencies in the general population and uniformly located across the entire spans of the chromosome $1 p$ and $19 q$ arms. The distribution of these SNPs enables discrimination between whole and partial chromosome deletions, and allows phenotype/genotype correlations, as previously reported $[11,35]$. This advantage is shared by other techniques, including SNP-array and array$\mathrm{CGH}$, previously used to study $1 \mathrm{p} / 19 \mathrm{q}$ status in gliomas [36] and, though these methods do not require a control DNA sample from the patient (unlike our technique), they are far less reliable when applied to samples with low DNA content or quality, such as FFPE samples. In routine diagnosis, indeed, application of methods such as SNPs or CGH array is challenged by the available amount of DNA, as these techniques require large quantities of starting material. By contrast, MS can accurately function 
Table 1: Molecular results obtained by MS assay for 1p/19q LOH, and IDH and TERT mutations

\begin{tabular}{|c|c|c|c|c|c|c|}
\hline \multirow{2}{*}{ SAMPLE } & \multirow{2}{*}{$\begin{array}{c}\text { HYSTOLOGICAL } \\
\text { TYPE }\end{array}$} & \multirow{2}{*}{$\begin{array}{c}\text { WHO } \\
\text { GRADE }\end{array}$} & \multicolumn{2}{|c|}{ LOH } & \multirow{2}{*}{ IDH mutations } & \multirow{2}{*}{ TERT mutations } \\
\hline & & & $1 p$ & $19 q$ & & \\
\hline 1 & ODG & II & LOH (3 SNPs) & LOH (6 SNPs) & IDH1 R132H* & TERT G228A* \\
\hline 2 & Anaplastic ODG & III & LOH (7 SNPs) & LOH (8 SNPs) & IDH1 R132H* & TERT G228A* \\
\hline 3 & ODG & II & LOH (10 SNPs) & LOH (5 SNPs) & IDH1 R132H* & TERT G228A \\
\hline 4 & Anaplastic ODG & III & LOH (6 SNPs) & LOH (7 SNPs) & IDH1 R132H* & TERT G228A* \\
\hline 5 & ODG & II & LOH (8 SNPs) & LOH (3 SNPs) & IDH1 R132C* & TERT G228A* \\
\hline 6 & ODG & II & LOH (6 SNPs) & LOH (4 SNPs) & IDH1 R132H* & TERT G228A* \\
\hline 7 & ODG & II & LOH (6 SNPs) & LOH (6 SNPs) & IDH1 R132H* & TERT G228A \\
\hline 8 & Anaplastic ODG & III & LOH (7 SNPs) & LOH (7 SNPs) & IDH1 R132H* & TERT G250A \\
\hline 9 & ODG & III & LOH (3 SNPs) & LOH (6 SNPs) & IDH2 R172W* & TERT G228A \\
\hline 10 & ODG & II & LOH (5 SNPs) & LOH (6 SNPs) & IDH1 R132H* & TERT G228A \\
\hline 11 & ODG & II & LOH (5 SNPs) & LOH (4 SNPs) & IDH1 R132H* & TERT G250A \\
\hline 12 & Anaplastic ODG & III & LOH (9 SNPs) & LOH (9 SNPs) & IDH2 R172K* & TERT G228A \\
\hline 13 & ODG & II & LOH (9 SNPs) & LOH (6 SNPs) & IDH1 R132H & TERT G228A \\
\hline 14 & ODG & II & LOH (7 SNPs) & LOH (7 SNPs) & IDH1 R132H* & TERT G228A* \\
\hline 15 & ODG & II & LOH (8 SNPs) & LOH (4 SNPs) & IDH1 R132H & TERT G228A \\
\hline 16 & ODG & II & LOH (9 SNPs) & LOH (7 SNPs) & IDH1 R132H* & TERT G250A \\
\hline 17 & Anaplastic AC & III & NO LOH (9 SNPs) & NO LOH (10 SNPs) & $\mathrm{WT}^{*}$ & WT \\
\hline 18 & $\mathrm{AC}$ & II & NO LOH (7 SNPs) & NO LOH (5 SNPs) & IDH1 R132C & WT \\
\hline 19 & Anaplastic AC & III & NO LOH (5 SNPs) & NO LOH (6 SNPs) & IDH1 R132H* & WT \\
\hline 20 & $\mathrm{AC}$ & II & NO LOH (8 SNPs) & NO LOH (5 SNPs) & IDH1 R132H* & WT \\
\hline 21 & $\mathrm{AC}$ & II & $\begin{array}{l}\text { NO LOH (13 } \\
\text { SNPs) }\end{array}$ & NO LOH (8 SNPs) & $I D H 1 \mathrm{R} 132 \mathrm{H}^{*}$ & WT \\
\hline 22 & $\mathrm{AC}$ & II & NO LOH (6 SNPs) & NO LOH (3 SNPs) & IDH1 R132H* & $\mathrm{WT}^{*}$ \\
\hline 23 & Anaplastic AC & III & NO LOH (6 SNPs) & NO LOH (3 SNPs) & IDH1 R132H* & WT \\
\hline 24 & $\mathrm{AC}$ & III & NO LOH (8 SNPs) & NO LOH (5 SNPs) & IDH1 R132H* & WT \\
\hline 25 & GBM & IV & NO LOH (6 SNPs) & NO LOH (4 SNPs) & $\mathrm{WT}^{*}$ & TERT G250A \\
\hline 26 & GBM & IV & NO LOH (7 SNPs) & NO LOH (6 SNPs) & $\mathrm{WT}^{*}$ & TERT G228A \\
\hline 27 & GBM & IV & NO LOH (8 SNPs) & NO LOH (8 SNPs) & $\mathrm{WT}^{*}$ & TERT G228A \\
\hline 28 & GBM & IV & NO LOH (5 SNPs) & NO LOH (7 SNPs) & $\mathrm{WT}^{*}$ & TERT G250A \\
\hline 29 & GBM & IV & NO LOH (5 SNPs) & NO LOH (2 SNPs) & $\mathrm{WT}^{*}$ & TERT G228A \\
\hline 30 & GBM & IV & NO LOH (9 SNPs) & NO LOH (7 SNPs) & $\mathrm{WT}^{*}$ & TERT G228A \\
\hline 31 & GBM & IV & NO LOH (4 SNPs) & NO LOH (5 SNPs) & $\mathrm{WT}^{*}$ & TERT G228A* \\
\hline 32 & GBM & IV & NO LOH (5 SNPs) & NO LOH (6 SNPs) & IDH1 R132H* & WT \\
\hline 33 & GBM & IV & NO LOH (8 SNPs) & NO LOH (4 SNPs) & $\mathrm{WT}^{*}$ & TERT G228A \\
\hline 34 & GBM & IV & NO LOH (8 SNPs) & NO LOH (5 SNPs) & $\mathrm{WT}^{*}$ & TERT G250A \\
\hline 35 & GBM & IV & NO LOH (8 SNPs) & NO LOH (6 SNPs) & $\mathrm{WT}^{*}$ & $\mathrm{WT}^{*}$ \\
\hline 36 & GBM & IV & NO LOH (9 SNPs) & NO LOH (2 SNPs) & $\mathrm{WT}^{*}$ & TERT G228A* \\
\hline 37 & GBM & IV & NO LOH (6 SNPs) & NO LOH (6 SNPs) & $\mathrm{WT}^{*}$ & TERT G228A* \\
\hline 38 & GBM & IV & NO LOH (7 SNPs) & NO LOH (8 SNPs) & $\mathrm{WT}^{*}$ & TERT G250A \\
\hline
\end{tabular}




\begin{tabular}{|c|c|c|c|c|c|c|}
\hline 39 & GBM & IV & NO LOH (9 SNPs) & NO LOH (7 SNPs) & $\mathrm{WT}^{*}$ & TERT G228A* \\
\hline 40 & GBM & IV & NO LOH (7 SNPs) & NO LOH (4 SNPs) & $\mathrm{WT}^{*}$ & TERT G250A* \\
\hline 41 & GBM & IV & NO LOH (6 SNPs) & NO LOH (6 SNPs) & $\mathrm{WT}^{*}$ & TERT G228A* \\
\hline 42 & GBM & IV & NO LOH (5 SNPs) & NO LOH (5 SNPs) & $\mathrm{WT}^{*}$ & TERT G228A \\
\hline 43 & GBM & IV & NO LOH (3 SNPs) & NO LOH (7 SNPs) & $\mathrm{WT}^{*}$ & TERT G228A* \\
\hline 44 & GBM & IV & NO LOH (4 SNPs) & NO LOH (10 SNPs) & WT & TERT G228A \\
\hline 45 & GBM & IV & NO LOH (7 SNPs) & NO LOH (6 SNPs) & $\mathrm{WT}^{*}$ & WT \\
\hline 46 & GBM & IV & NO LOH (4 SNPs) & NO LOH (3 SNPs) & $\mathrm{WT}^{*}$ & $\mathrm{WT}^{*}$ \\
\hline 47 & GBM & IV & NO LOH (6 SNPs) & NO LOH (8 SNPs) & $\mathrm{WT}^{*}$ & TERT G228A* \\
\hline 48 & GBM & IV & NO LOH (6 SNPs) & NO LOH (4 SNPs) & $\mathrm{WT}^{*}$ & TERT G228A* \\
\hline 49 & GBM & IV & NO LOH (7 SNPs) & NO LOH (5 SNPs) & $\mathrm{WT}^{*}$ & TERT G228A* \\
\hline 50 & GBM & IV & NO LOH (5 SNPs) & NO LOH (3 SNPs) & WT* & TERT G228A \\
\hline
\end{tabular}

ODG, oligodendroglioma; AC, astrocytoma; GBM, glioblastoma.

The number of informative SNPs for LOH analyses is shown in parentheses for each sample.

*confirmed by Sanger sequencing.

using a very small amount of DNA (approximately $5 \mathrm{ng}$ ). FISH is an additional technique commonly exploited to study chromosome deletions in tumor tissues, because it does not require normal counterpart and can be performed also when the amount of neoplastic cells is low. Despite these advantages, FISH probes usually target solely the telomeric region of both chromosome arms, making the distinction between whole and partial chromosome deletions tricky. Furthermore, FISH is both laborious and time-consuming and in some cases the results are not conclusive and need PCR-based approach to study the $\mathrm{LOH}$ in order to complete the analysis [37].

A limitation of the MS test is that it requires a normal control sample to be applied. As a normal tissue we propose the use of patient blood sample, which could be easily obtained during the surgery and can be stored until

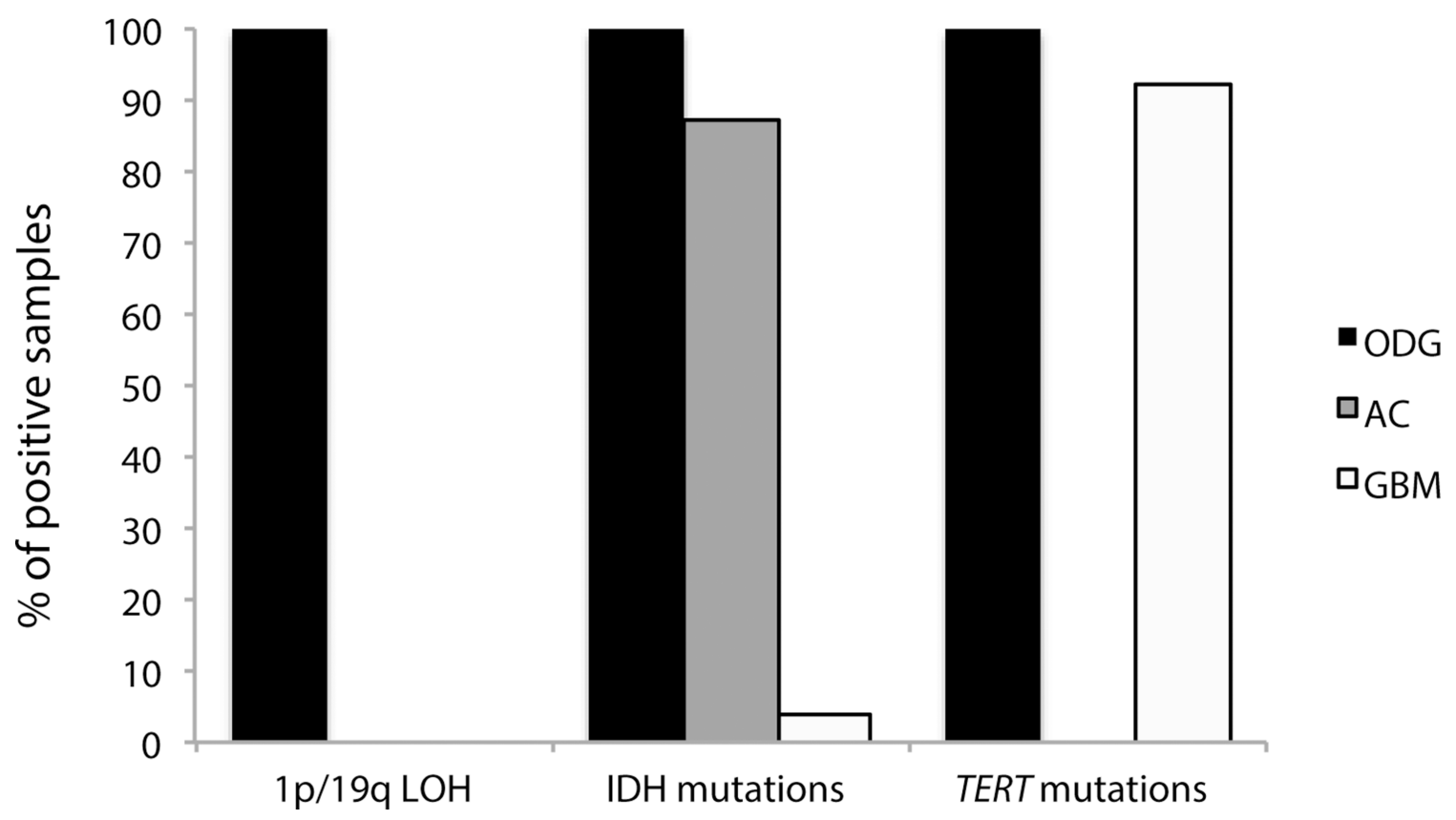

Figure 3: Distribution of the molecular markers analyzed in the three histological categories (ODG, AC and GBM). Anaplastic ODGs and anaplastic ACs were included in the ODG and AC classes, respectively. 
the beginning of the analysis. However, when the blood sample is not available, the normal counterpart could be dissected from FFPE sample. If blood sample or other normal counterparts are not available, FISH or array-CGH should be performed. Another possible limitation of the MS test compared to FISH or array-CGH is that, similar to STRs analysis and also to NGS approaches [28-30], it reveals allelic imbalances but cannot distinguish between chromosome deletions or amplifications. Although $1 \mathrm{p}$ and $19 \mathrm{q}$ duplications are also possible features of glioma, concurrent duplications of both chromosome regions are a really rare event, thus the presence of concurrent imbalances is almost certainly due to a codeletion of both chromosome arms. The $1 \mathrm{p} / 19 \mathrm{q}$ codeletion is precisely detected by MS (as demonstrated by our results) and it is currently the only chromosome imbalance with diagnostic value in glioma. However, when copy number aberrations are found in only one of the two chromosome arms, further analyses should be performed, to clarify the MS results.

In addition, the possibility of simultaneously genotyping a number of genetic loci allows the combination of all the required diagnostic analyses in one experiment, making MS the best choice to facilitate rapid diagnosis, also with limiting biological starting material. Indeed, using the MS test it is possible to analyze IDH mutations and $1 \mathrm{p} / 19 \mathrm{q}$ status simultaneously, allowing the concomitant evaluation of the molecular markers deemed mandatory by the 2016 CNS WHO classification system.

Considering that MS would be simple to implement for new hotspot mutations, we extended our MS assay to evaluate mutations in the TERT promoter, which are not yet required by WHO, but are characteristic of both ODGs and GBMs and have recently been determined to have specific prognostic value in the molecular classification of gliomas [8, 22, 26]; moreover, TERT is also a potential therapeutic target, as recently demonstrated by the results obtained by Imetelstat treatment on various type of hematological and solid tumors [18, 19, 38, 39].

We did not include ATRX and TP53 evaluation in the MS assay, since there are not hotspot mutations at these genes, and thus traditional sequencing or immunohistochemical staining would be more appropriate approaches for evaluation of these genes. MGMT promoter methylation status was also not included because analysis of DNA methylation requires a different MS protocol that cannot be combined using the genotyping approach.
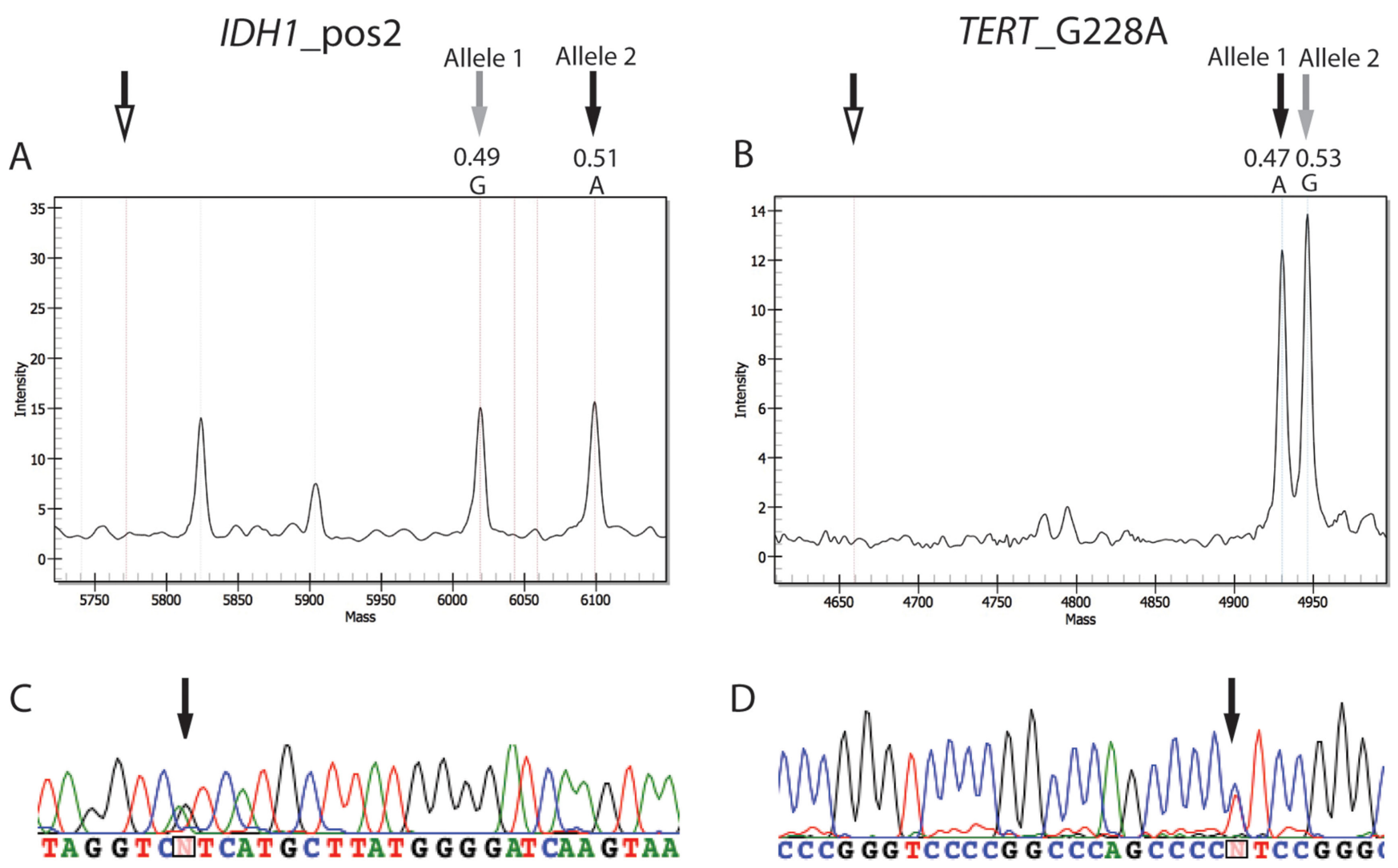

Figure 4: Spectra and electropheromgrams representative of IDH and TERT mutations. (A) Mutation in position 2 (c.395G $>$ A) of codon 132 of IDH1 in case 4. (B) Mutation in position G228 (c.-124C $>$ T) of the TERT promoter in case 37. Unfilled arrows, position of extension primers; gray arrows, wildtype alleles (Allele 1 for IDH1 c.395 and Allele 2 for TERT c.-124); black arrows, mutant alleles. The allele frequencies of the wildtype and mutant alleles are indicated. Other peaks present in the spectra of $I D H 1$ pos 2 represent the allele signals of another SNP of the MS test. (C and D) display the results obtained by sequencing of the IDH1 in case 4 and TERT in case 37 , respectively. Black arrows correspond to the position of the mutated allele in the sequence. 
In conclusion, the test described here represents a potential compromise between high-throughput technologies and cost- and time-effectiveness. The assay allows the concomitant evaluation of key markers of glioma characterization, comprising $1 \mathrm{p} / 19 \mathrm{q}$ LOH status, and IDH and TERT mutations, conceivably in 2 working days, with limited cost per sample (about 80 euro per sample). The versatility of the MS technique makes it implementable with other new diagnostic markers; indeed, the MS tests could be also extended with the detection of other hotspot mutations, such as BRAF V600E, typical of few types of glioma, as epitheliod glioblastoma, or H3 K27M for diffuse midline gliomas, characteristic of pediatric patients [6].

Taken together, this approach may represent a step towards rapid, reliable, and cost-effective glioma diagnosis. The advantages and disadvantages of MS and the comparison with other techniques used to detect $\mathrm{LOH}$ are also detailed in Supplementary Table 2. Moreover, in this study, we demonstrated the feasibility of accurate detection of LOH using MS. Since also other chromosome deletions could become relevant for glioma diagnosis, such as 10q loss in GBMs or 9p loss in ODGs [20, 29], and, furthermore, deletions are also an important marker of genomic instability in other cancer types [40-42], the results using the MS approach in this study provide proof of principle for its future clinical application.

\section{MATERIALS AND METHODS}

\section{Population}

Fifty patients diagnosed with diffuse glioma from December 2013 to November 2016 at the Fondazione IRCCS Ca' Granda, Ospedale Maggiore Policlinico di Milano were enrolled in the study on the basis of the availability of tumor and peripheral blood specimens. The study was approved by the Institutional Ethics Committee (Fondazione IRCCS Ca' Granda, Ospedale Maggiore Policlinico no. 526/2015).

Twenty-four patients had LGGs (diffuse glioma, WHO grade II-III), including 12 ODGs, four anaplastic ODGs, five ACs, and three anaplastic ACs; the other 26 samples were high grade gliomas (HGGs; diffuse glioma, WHO grade IV), termed glioblastomas (GBMs) (Table 1). The median age at surgery was 53 years (range, 21 to 81 years); twenty-two patients were females and 28 males; forty-six patients underwent partial or total resection, while four patients underwent biopsy, due to the tumor location. This study focused on the development of a useful and updated molecular test for glioma diagnosis. Clinical aspects, such as overall survival and therapy response, were not considered.

\section{Biological specimens}

Tumor DNA was extracted from FFPE sections using a Biostic FFPE tissue DNA isolation kit (MO
BIO Laboratories, Carlsbad, CA, USA), following the manufacturer's instructions. FFPE tissue samples had previously been stained using hematoxylin and eosin and analyzed independently by two pathologists. The tumor cell content in all samples was at least $70 \%$.

DNA from PBLs was isolated using the QiAMP DNA Mini Kit (Qiagen, Hilden, Germany), according to the manufacturer's protocol and used to test for the $1 p / 19 q$ codeletion.

\section{MassARRAY procedures}

Chromosome $1 \mathrm{p} / 19 \mathrm{q}$ codeletion, and IDH and TERT mutations, were screened using a MassARRAY iPLEX platform (Agena Bioscience, San Diego, CA, USA), based on MALDI-TOF mass spectrometry. The results obtained using the MS assay were then validated by comparison with previous results obtained by STR genotyping or array-CGH.

\section{1p/19q codeletion}

To evaluate chromosome $1 \mathrm{p} / 19 \mathrm{q}$ codeletion in the tumor samples, LOH was tested for by analysis of a panel of 16 selected SNPs on $1 p$ and 11 SNPs on $19 q$, both spanning the chromosome arms from their centromeric to their telomeric regions (Figure 5A and Supplementary Table 3). The homogeneous distribution of the SNPs along the two chromosome arms also provided the ability to discriminate between whole and partial chromosome arm imbalances. LOH assessment was performed by considering informative those SNPs heterozygous in PBL DNA, and comparing their genotypes in PBL DNA with those in tumor DNA.

Using data from the Ensembl database (http://www. ensembl.org/index.html), biallelic SNPs, with minor allele frequencies (MAFs) close to 0.5, were selected (Supplementary Table 3) since, in an ideal population, in accordance with Hardy-Weinberg Equilibrium, these SNPs would have a frequency of heterozygosity close to 0.5 . Therefore, based on MAF values, the probability of identifying an individual homozygous for all of the SNPs was verified as being very low $(<1: 20,000$ for $1 \mathrm{p}$ and $<1: 1,700$ for $19 q$ ), thus ensuring that the MS assay had high sensitivity for detection of $\mathrm{LOH}$.

Furthermore, the percentages of samples in our population heterozygous for each SNP were calculated, and all were confirmed to be around 50\% (range, 32-62\%) (Figure 5B), reflecting the assumption inferred from the MAFs in the general population.

To establish when a SNP could be considered heterozygous based on the MS results, the raw allele frequencies determined using the MassARRAY Typer software were exploited, which represented the percentage of each allele detected by the instrument for each specific SNP in the analyzed sample. Where Allele 1 had the lower molecular weight (appearing on the left of the spectrum) 
and Allele 2 the higher molecular weight (appearing on the right of the spectrum), allele frequencies ranged from 0 to 1 , where 0 indicates the absence, and 1 the presence, of the observed allele only (i.e., homozygosity or hemizygosity). For example, if in a given sample the frequency of Allele 1 of SNP " $x$ " is 0.54 , the frequency of Allele 2 of this SNP will be 0.46 ; hence the sum of the allele frequencies is always 1 . A SNP was verified as being considered heterozygous when the observed allele frequencies were between 0.3 and 0.7 , as reported by the MassARRAY ${ }^{\circledR}$ Typer 3.4 Software [43]. Furthermore, for each heterozygous SNP the variability of allele frequencies was investigated by evaluating the results generated using heterozygous PBL samples. As depicted in Figure 5C, the allele frequencies of each SNP generated by the instrument were stable among the normal control heterozygous samples, with standard deviations lower than $10 \%$, confirming the reliability of the MS assay (for an example of allele frequency see Figure 2 or Figure 4, the intensity of the signal of each allele is reported on the $\mathrm{y}$ axis; from the intensity of each signal the MS software derives the respective allele frequency).
The following equation was used to quantitatively define the LOH status:

$$
\frac{N_{2} / N_{1}}{N_{2} / N_{1}+T_{2} / T_{1}}
$$

Where $\mathrm{N}_{1}$ and $\mathrm{N}_{2}$ are the frequencies of Allele 1 and Allele 2 found in PBL DNA and $\mathrm{T}_{1}$ and $\mathrm{T}_{2}$ are those of the corresponding alleles in tumor DNA. LOH was defined as detected when the value obtained using this formula was $<0.3$ or $>0.7$.

\section{IDH and $T E R T$ mutations}

The analysis of codons 132 of IDH1 (c.394C and c.395G; NP_001269316) and 172 of IDH2 (c.514A, c.515G, and c.516G; NP_002159), and of the c.$124 \mathrm{C}>\mathrm{T}$ (G228A) and c. $-146 \mathrm{C}>\mathrm{T}$ (G250A) TERT promoter (NP_937983) mutations, was included in the MS multiplexed assay. Negative and positive controls

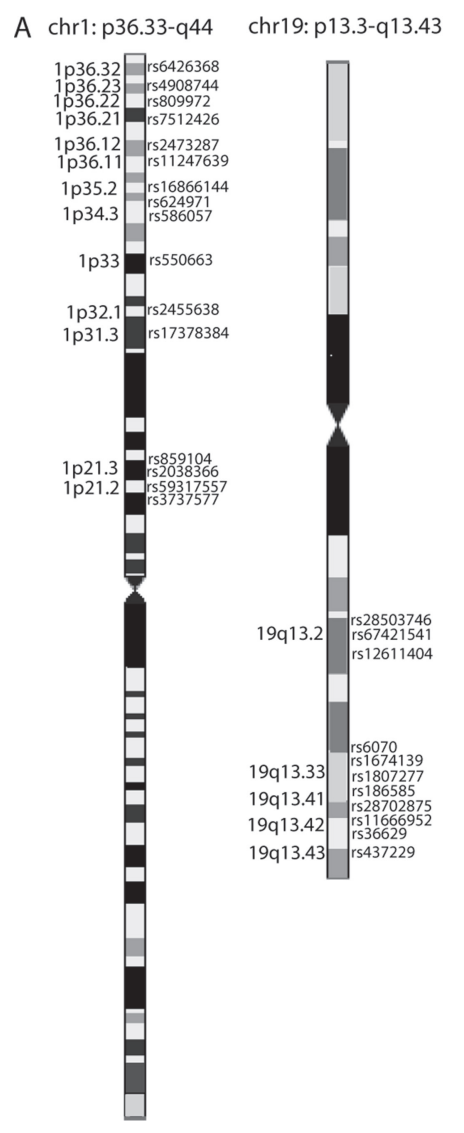

B

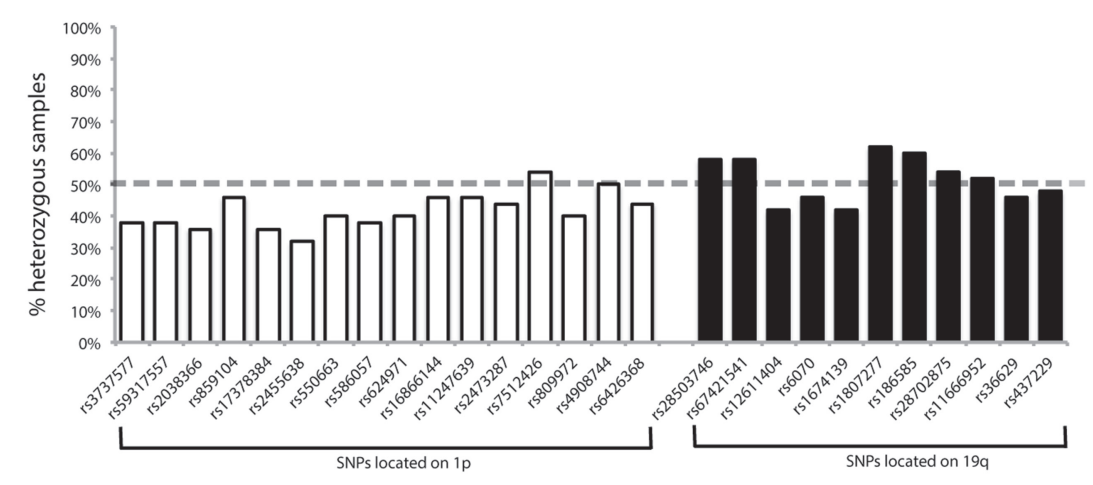

C

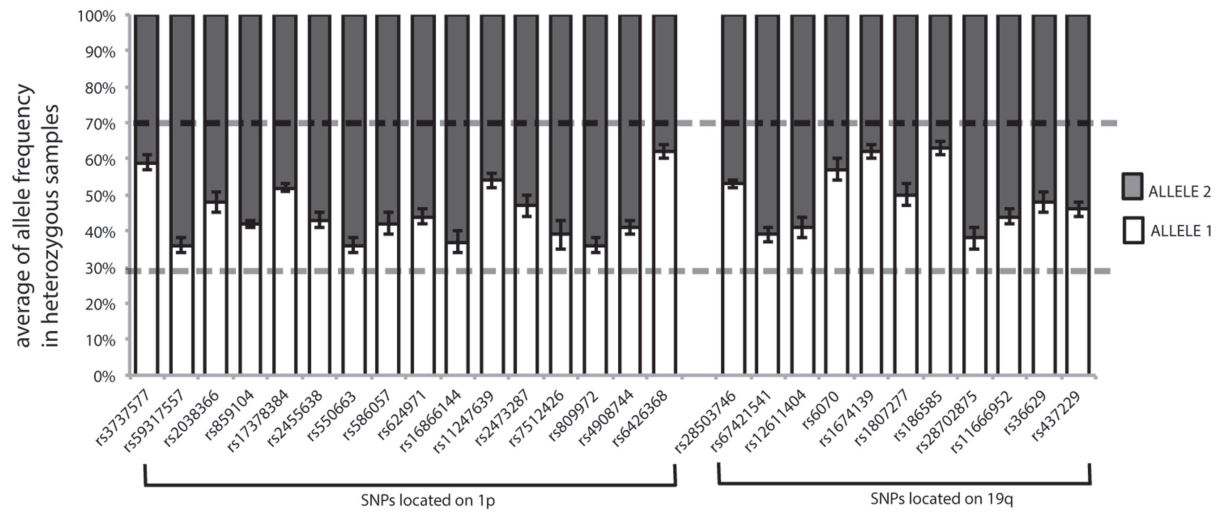

Figure 5: Chromosome location of SNPs, percentages of heterozygosity for each SNP, and mean allele frequencies for each SNP in heterozygous samples. (A) SNP chromosome locations. Chromosome images originate from the UCSC database. The chromosome bands in which SNPs are located are indicated. (B) Graphical representation of the percentages of heterozygous samples for each SNP, calculated from the results obtained from the analysis of blood DNA samples from our population. Dotted line indicates $50 \%$. (C) Graphical representation of mean allele frequencies for each SNP obtained from all heterozygous PBL samples in our population. The error bars indicate the standard deviation from the mean allele frequencies for each SNP. Dotted lines show the range of frequencies in which a sample was considered heterozygous (between $30 \%$ and $70 \%$ ). 
were included in each analysis; PBL DNA was used as a negative control while DNA samples from mutated tumors (previously identified by Sanger sequencing) were used as positive controls.

\section{MassARRAY reactions}

PCR and extension primers were designed using Assay Design Suite v2.0, (https:/www.agenacx.com/ Logon.aspx?ReturnUrl=\%2fTools), and multiplexed to obtain three PCR mixes. As indicated by the guideline procedures, a specific oligo tag sequence (5ф-ACGTTGGATG-) was added to the $5 \phi$ end of each PCR primer to optimize the PCR reaction. Primers sequences are reported in Supplementary Table 3. Briefly, PCR amplification was conducted in $5 \mu \mathrm{l}$ reactions containing 5-30 ng of DNA (depending on DNA availability), $100 \mathrm{nM}$ PCR primers, $100 \mathrm{nM}$ dNTP mix, PCR buffer, $25 \mathrm{mM} \mathrm{MgCl}_{2}$, and $5 \mathrm{U}$ Taq DNA polymerase (Agena Bioscience, San Diego, CA, USA). The mixture was incubated as follows: $95^{\circ} \mathrm{C}$ for $2 \mathrm{~min}, 45$ cycles of $95^{\circ} \mathrm{C}$ for $30 \mathrm{sec}, 56^{\circ} \mathrm{C}$ for $30 \mathrm{sec}$, and $72^{\circ} \mathrm{C}$ for $60 \mathrm{sec}$, with a final extension step at $72^{\circ} \mathrm{C}$ for $5 \mathrm{~min}$. Remaining unincorporated dNTPs were dephosphorylated and inactivated by treatment with $1.7 \mathrm{U}$ of shrimp alkaline phosphatase at $37^{\circ} \mathrm{C}$ for $40 \mathrm{~min}$ and then $85^{\circ} \mathrm{C}$ for 5 min. Finally, the single base extension (SBE) reaction mix, including iPLEX Buffer Plus, iPLEX Termination Mix, Extension Primers mix, and iPLEX enzyme (Agena Bioscience, San Diego, CA, USA), was added to the PCR amplification products. The SBE reaction was carried out under the following conditions: $94^{\circ} \mathrm{C}$ for $30 \mathrm{sec} ; 40$ cycles at $94^{\circ} \mathrm{C}$ for $5 \mathrm{sec}\left[52^{\circ} \mathrm{C}\right.$ for $5 \mathrm{sec}$ and $80^{\circ} \mathrm{C}$ for $5 \mathrm{sec}$ (repeated five times per cycle)]; and a final extension step at $72^{\circ} \mathrm{C}$ for $3 \mathrm{~min}$. Samples were spotted on a SpectroCHIP (Agena Bioscience, San Diego, CA, USA), and finally analyzed by mass spectrometry. The spectral profiles generated by MALDI-TOF mass spectrometry were analyzed using Typer v.4.0 software (Agena Bioscience, San Diego, CA, USA).

\section{Evaluation of 1p/19q LOH by STR analysis}

PCRs were performed using $100 \mathrm{ng}$ of DNA from both tumor and PBL samples, and the products were analyzed by capillary gel electrophoresis using Gene Mapper software on an ABI 3130XL system (Applied Biosystems, Foster City, CA, USA). Six (D1S1592, D1S548, D1S2694, D1S2666, D1S1612, and D1S468) and three (D19S412, D19S596, and D19S206) STRs were used to investigate the presence of deletions on chromosomes $1 \mathrm{p}$ and $19 \mathrm{q}$, respectively. The genomic locations of the STRs and the primer sequences used to amplify them are provided in Supplementary Table 4. LOH was assessed according to the peak-height ratio, as previously described [44]. In brief, the peak height derived from each allele amplified from both tumor and corresponding normal DNA was compared. The formula $(\mathrm{T} 1 / \mathrm{T} 2) /(\mathrm{N} 1 / \mathrm{N} 2)$ was applied, where $\mathrm{T} 1$ and $\mathrm{T} 2$ are the peak heights of the alleles detected in tumor DNA, and $\mathrm{N} 1$ and $\mathrm{N} 2$ are the peak heights produced from PBL DNA. LOH was considered present when the result of the calculation was $<0.50$. For values $>1.00$, the ratio was converted to $1 /[(\mathrm{T} 1 / \mathrm{T} 2) /(\mathrm{N} 1 / \mathrm{N} 2)]$ and, again, $\mathrm{LOH}$ was considered present if the resulting value was $<0.50$.

\section{FISH analysis}

FISH was performed in ten cases on $4-\mu$ m-thick sections of FFPE specimens, depending on the material availability. Five displayed $1 \mathrm{p} / 19 \mathrm{q} \mathrm{LOH}$ and five were without $1 \mathrm{p} / 19 \mathrm{q} \mathrm{LOH}$, by MS and STR analyses. For each samples two slides were prepared, one for the detection of $1 p$ deletion and the other one for $19 q$ deletion. The sections were deparaffinized, treated with sodium thiocyanate and then digested with pepsin solution. Dual-color-probe hybridization was performed using ZytoLight SPEC 1p36/1q25 and 19q13/19p13 probes (ZytoVision, Bremerhaven, Germany). The spectrumgreen-probes label the control regions 1q25 and 19p13 of each chromosome, while spectrum-red-probes mark the targets 1 p36 and 19q13. Both probes for chromosomes 1 and 19 were denatured at $75^{\circ} \mathrm{C}$ for 10 minutes followed by an overnight hybridization at $37^{\circ} \mathrm{C}$. Nuclei were counterstained with Leica mounting medium containing 4',6-diamidino-2-phenylindole (DAPI) (Leica, Wetzlar, Germany) and examined under a Leica DM4000B Fluorescence microscope (Leica, Wetzlar, Germany) equipped with appropriate filters (DAPI, green and red). Signals of 100 non-overlapping nuclei with at least two control/green signals were enumerated for both chromosomes slides.

Interpretation of FISH images was performed accordingly to Ambros et al, 2001 [37]: normal pattern was defined by the presence of an equal number of control/ green and target/red signals (i.e. control/target ratio: $2 / 2$, $3 / 3,4 / 4$, etc), deletion pattern was characterized by the presence of at least two control/green signals but only one or zero target/red signals (i.e. control/target ratio: $2 / 1$, $2 / 0,3 / 1$, etc); finally imbalance pattern was identified by the presence of more than 1 target/red signal (i.e. control/ target ratio: $3 / 2,4 / 2,4 / 3$, etc).

A sample was considered positive for $1 p / 19 q$ codeletion when more than $50 \%$ of nuclei per chromosome arm displayed a typical deletion pattern [37, 45, 46].

\section{Array-CGH}

In a subset of cases (two GBM and two ODGs), $1 \mathrm{p} / 19 \mathrm{q}$ status was also confirmed by array-CGH. Array-CGH analysis was performed using 180 mer oligonucleotide probe technology (SurePrint G3 Human 
CGH $4 \times 180 \mathrm{~K}$, Agilent Technologies, Santa Clara, CA, USA), according to the manufacturer's instructions. Raw data were generated using Agilent Feature Extraction and analyzed using Cytogenomics 3.0.4.1, with the ADM-2 algorithm (Agilent Technologies, Santa Clara, CA, USA). To improve the accuracy of the results, the Diploid Peak Centralization algorithm was also applied.

The aberration filter was set to detect a minimum of five consecutive probes/region, and the minimum absolute average log ratio (MAALR) was \pm 0.25 . A second analysis was run with a MAALR of \pm 0.15 (again with a minimum number of five probes/region), to detect low level of mosaicism. Only copy number variants not already reported in the public database of genomic variants (http://projects.tcag.ca/variation/) were listed. Genomic coordinates are according to the build 37 assembly (March 2009) of the Human Genome Reference consortium (GRch37/hg19).

\section{IDH and TERT sequencing}

The IDH and TERT hotspot mutations identified by MS were confirmed by sequencing in a subset of samples, based on DNA availability. The DNA regions spanning between the hotspot mutations in IDH1, IDH2 and TERT genes were amplified using the primers reported in Supplementary Table 4 . The PCR mixture of $20 \mu$ l volume contained $100 \mathrm{ng}$ of DNA, 1X of PCR buffer, $1.5 \mathrm{mM}$ $\mathrm{MgCl}_{2}, 0.2 \mathrm{mM}$ of each deoxyribonucleoside triphosphate, $0.5 \mu \mathrm{M}$ of each primer and 0.2 units of AmpliTaq Gold DNA polymerase (Applied Biosystems, Foster City, CA, US). PCR program consisted of an initial denaturation performed at $95^{\circ} \mathrm{C}$ for $5 \mathrm{~min}$, followed by 35 cycles of denaturation at $95^{\circ} \mathrm{C}$ for $20 \mathrm{sec}$, annealing for $20 \mathrm{sec}$ and extension at $72^{\circ} \mathrm{C}$ for $30 \mathrm{sec}$, and a final extension step at $72^{\circ} \mathrm{C}$ for 5 min. PCR products were purified using the MinElute PCR Purification Kit (Qiagen, Hilden, Germany) and sequenced using the automated sequencer ABIPRISM 3130XL Genetic Analyzer (Applied Biosystems, Foster City, CA, US).

\section{Abbreviations}

Array-CGH, Array comparative genomic hybridization; AC, Astrocytoma; CNS, Central nervous system; FFPE, Fixed-formalin paraffin-embedded; FISH, Fluorescence Is Situ Hybridization; GBM, Glioblastoma; IDH, IDH1 and IDH2 genes; LOH, Loss of heterozygosity; MAF, Minor allele frequency; MALDITOF, Matrix-assisted laser desorption ionization timeof-flight; MS, MassARRAY; ODG, Oligodendroglioma; SNP, Single nucleotide polymorphism; STR, Short tandem repeat; WHO, World Health Organization.

\section{Author contributions}

Monica Miozzo, Silvia Tabano and Silvano Bosari have conceived and initiated the project. All the MS experiments in this study were performed by Chiara Pesenti and the results were analyzed by Chiara Pesenti and Silvia Tabano. The STRs analyses were jointly performed by Chiara Pesenti and Leda Paganini. Laura Fontana contributed to the design of the experiments and, in addition, Maura Menghi revised the assay in the light of a possible translation into a CE-IVD device. Emanuela Veniani performed and evaluated the FISH analysis. Stefano Ferrero and Letterio Runza made the histology of the samples included in this study. Giovanni Marfia and Manuela Caroli provided the biological material and all the clinical data. Rosamaria Silipigni and Silvana Guerneri performed the array-CGH analysis. Chiara Pesenti analyzed all the data and generated the final figures and tables, and she wrote significant portions of the manuscript. Monica Miozzo and Silvia Tabano contributed to the writing and the editing of the manuscript. All the authors revised and accepted the final version of the manuscript.

\section{CONFLICTS OF INTEREST}

Maura Menghi is employee of Diatech Pharmacogenetics. The remaining authors declare no conflicts of interest.

\section{FUNDING}

Ministero della Salute Regione Lombardia Ricerca Finalizzata 2011-2012, RF-2011-02347106, PI Monica Miozzo.

\section{REFERENCES}

1. Ostrom QT, Gittleman H, Farah P, Ondracek A, Chen Y, Wolinsky Y, Stroup NE, Kruchko C, Barnholtz-Sloan JS. CBTRUS Statistical Report: Primary Brain and Central Nervous System Tumors Diagnosed in the United States in 2008-2012. Neouro-Oncology. 2013; 12:28-36. https://doi. org/10.1093/neuonc/nou223.

2. Louis DN, Ohgaki H, Wiestler OD, Cavenee WK, Burger PC, Jouvet A, Scheithauer BW, Kleihues P. The 2007 WHO classification of tumours of the central nervous system. Acta Neuropathol. 2007; 114:97-109. https:/doi. org/10.1007/s00401-007-0243-4.

3. Wiestler B, Capper D, Sill M, Jones DTW, Hovestadt V, Sturm D, Koelsche C, Bertoni A, Schweizer L, Korshunov A, Weiß EK, Schliesser MG, Radbruch A, et al. Integrated DNA methylation and copy-number profiling identify three clinically and biologically relevant groups of anaplastic glioma. Acta Neuropathol. 2014; 128:561-71. https://doi.org/10.1007/s00401-014-1315-X.

4. Ceccarelli M, Barthel FP, Malta TM, Sabedot TS, Salama SR, Murray BA, Morozova O, Newton Y, 
Radenbaugh A, Pagnotta SM, Anjum S, Wang J, Manyam G, et al. Molecular Profiling Reveals Biologically Discrete Subsets and Pathways of Progression in Diffuse Glioma. Cell. 2016; 164:550-63. https://doi.org/10.1016/j. cell.2015.12.028.

5. Fontana L, Tabano S, Bonaparte E, Marfia G, Pesenti C, Falcone R, Augello C, Carlessi N, Silipigni R, Guerneri S, Campanella R, Caroli M, Sirchia SM, et al. MGMTmethylated alleles are distributed heterogeneously within glioma samples irrespective of IDH Status and chromosome 10q Deletion. J Neuropathol Exp Neurol. 2016; 75: 791-800. https://doi.org/10.1093/jnen/nlw052.

6. Louis DN, Perry A, Reifenberger G, von Deimling A, Figarella-Branger D, Cavenee WK, Ohgaki H, Wiestler OD, Kleihues P, Ellison DW. The 2016 World Health Organization Classification of Tumors of the Central Nervous System: a summary. Acta Neuropathol. 2016; 131:803-20. https://doi.org/10.1007/s00401-016-1545-1.

7. Yan H, Parsons DW, Jin G, McLendon R, Rasheed BA, Yuan W, Kos I, Batinic-Haberle I, Jones S, Riggins GJ, Friedman H, Friedman A, Reardon D, et al. IDH1 and IDH2 Mutations in Gliomas. N Engl J Med. 2009; 360:765-73. https://doi.org/10.1056/NEJMoa0808710.

8. Labussière M, Boisselier B, Mokhtari K, Di Stefano AL, Rahimian A, Rossetto M, Ciccarino P, Saulnier O, Paterra R, Marie Y, Finocchiaro G, Sanson M. Combined analysis of TERT, EGFR, and IDH status defines distinct prognostic glioblastoma classes. Neurology. 2014; 83:1200-6. https:// doi.org/10.1212/WNL.0000000000000814.

9. Wesseling P, van den Bent M, Perry A. Oligodendroglioma: pathology, molecular mechanisms and markers. Acta Neuropathol. 2015; 129:809-27. https://doi.org/10.1007/ s00401-015-1424-1.

10. Molenaar RJ, Radivoyevitch T, Maciejewski JP, van Noorden CJF, Bleeker FE. The driver and passenger effects of isocitrate dehydrogenase 1 and 2 mutations in oncogenesis and survival prolongation. Biochim Biophys Acta. 2014; 1846:326-41. https://doi.org/10.1016/j.bbcan.2014.05.004.

11. Jenkins RB, Blair H, Ballman K V., Giannini C, Arusell RM, Law M, Flynn H, Passe S, Felten S, Brown PD, Shaw EG, Buckner JC. A $t(1 ; 19)(q 10 ; p 10)$ mediates the combined deletions of $1 p$ and $19 q$ and predicts a better prognosis of patients with oligodendroglioma. Cancer Res. 2006; 66: 9852-61. https://doi.org/10.1158/0008-5472.CAN-06-1796.

12. Horn S, Figl A, Rachakonda PS, Fischer C, Sucker A, Gast A, Kadel S, Moll I, Nagore E, Hemminki K, Schadendorf D, Kumar R. TERT Promoter Mutations in Familial and Sporadic Melanoma. Science. 2013; 339:959-61. https://doi. org/10.1126/science.1230062.

13. Griewank KG, Murali R, Schilling B, Scholz S, Sucker A, Song M, Susskind D, Grabellus F, Zimmer L, Hillen U, Steuhl KP, Schadendorf D, Westekemper H, et al. TERT promoter mutations in ocular melanoma distinguish between conjunctival and uveal tumours. Br J Cancer. 2013; 109:497-501. https://doi.org/10.1038/bjc.2013.312.
14. Killela PJ, Reitman ZJ, Jiao Y, Bettegowda C, Agrawal N, Diaz Jr. LA, Friedman AH, Friedman H, Gallia GL, Giovanella BC, Grollman AP, He TC, He Y, et al. TERT promoter mutations occur frequently in gliomas and a subset of tumors derived from cells with low rates of selfrenewal. Proc Natl Acad Sci U S A. 2013; 110:6021-6. https://doi.org/10.1073/pnas.1303607110.

15. Yuan Y, Qi C, Maling G, Xiang W, Yanhui L, Ruofei L, Yunhe M, Jiewen L, Qing M. TERT mutation in glioma: Frequency, prognosis and risk. J Clin Neurosci. 2016; 26:57-62. https://doi.org/10.1016/j.jocn.2015.05.066.

16. Bell RJA, Rube HT, Kreig A, Mancini A, Fouse SF, Nagarajan RP, Choi S, Hong C, He D, Pekmezci M, Wiencke JK, Wrensch MR, Chang SM, et al. The transcription factor GABP selectively binds and activates the mutant TERT promoter in cancer. Science. 2015; 348:1036-9. https://doi.org/10.1126/science.aab0015.

17. Tergaonkar V. NFKB drives TERT promoter reactivation in cancer. Cell Cycle. 2016; 15:156-7. https://doi.org/10.1080 /15384101.2015.1118908.

18. Maida Y, Yasukawa M, Furuuchi M, Lassmann T, Possemato R, Okamoto N, Kasim V, Hayashizaki Y, Hahn WC, Masutomi K. An RNA-dependent RNA polymerase formed by TERT and the RMRP RNA. Nature. 2009; 461:1-7. https://doi.org/10.1038/nature08283.

19. Li Y, Zhou QL, Sun W, Chandrasekharan P, Cheng HS, Ying Z, Lakshmanan M, Raju A, Tenen DG, Cheng SY, Chuang KH, Li J, Prabhakar S, et al. Non-canonical NF$\kappa \mathrm{B}$ signalling and ETS1/2 cooperatively drive C250T mutant TERT promoter activation. Nat Cell Biol. 2015; 17: 1327-38. https://doi.org/10.1038/ncb3240.

20. Masui K, Mischel PS, Reifenberger G. Molecular classification of gliomas. 1st ed. Handb Clin Neurol. 2016; 97-120. https://doi.org/10.1016/B978-0-12-8029978.00006-2.

21. Labussière $\mathrm{M}$, Di Stefano $\mathrm{AL}$, Gleize $\mathrm{V}$, Boisselier $\mathrm{B}$, Giry M, Mangesius S, Bruno A, Paterra R, Marie Y, Rahimian A, Finocchiaro G, Houlston RS, Hoang-Xuan K, et al. TERT promoter mutations in gliomas, genetic associations and clinico-pathological correlations. Br J Cancer. 2014; 111:2024-32. https://doi.org/10.1038/bjc.2014.538.

22. Arita $H$, Yamasaki $K$, Matsushita $Y$, Nakamura $T$, Shimokawa A, Takami H, Tanaka S, Mukasa A, Shirahata M, Shimizu S, Suzuki K, Saito K, Kobayashi $\mathrm{K}$, et al. A combination of TERT promoter mutation and MGMT methylation status predicts clinically relevant subgroups of newly diagnosed glioblastomas. Acta Neuropathol Commun. 2016; 4:79-93. https://doi. org/10.1186/s40478-016-0351-2.

23. Zhang ZY, Chan AKY, Ding XJ, Qin ZY, Hong CS, Chen LC, Zhang X, Zhao FP, Wang Y, Wang Y, Zhou LF, Zhuang Z, Ng HK, et al. TERT promoter mutations contribute to IDH mutations in predicting differential responses to adjuvant therapies in WHO grade II and III diffuse gliomas. Oncotarget. 2015; 6:24871-83. https://doi. org/10.18632/oncotarget.4549. 
24. Chan DT, Poon WS, Zhou L, Ng H. TERT promoter mutations contribute to subset prognostication of lowergrade gliomas. Mod Pathol. 2015; 28:177-86. https://doi. org/10.1038/modpathol.2014.94.

25. Dunn J, Baborie A, Alam F, Joyce K, Moxham M, Sibson R, Crooks D, Husband D, Shenoy A, Brodbelt A, Wong H, Liloglou T, Haylock B, et al. Extent of MGMT promoter methylation correlates with outcome in glioblastomas given temozolomide and radiotherapy. Br J Cancer. 2009; 101:124-31. https://doi.org/10.1038/sj.bjc.6605127.

26. Eckel-Passow JE, Lachance DH, Molinaro AM, Walsh KM, Decker PA, Sicotte H, Pekmezci M, Rice T, Kosel ML, Smirnov IV, Sarkar G, Caron AA, Kollmeyer TM, et al. Glioma groups based on 1p/19q, IDH, and TERT promoter mutations in tumors. N Engl J Med. 2015; 372:2499-508. https://doi.org/10.1056/NEJMoa1407279.

27. Killela PJ, Pirozzi CJ, Healy P, Reitman ZJ, Lipp E, Rasheed BA, Yang R, Diplas BH, Wang Z, Paula K, Zhu H, Wang CY, Carpenter AB, et al. Mutations in IDH1, IDH2, and in the TERT promoter define clinically distinct subgroups of adult malignant gliomas. Oncotarget. 2014; 5:1515-25. https://doi.org/10.18632/oncotarget.1765.

28. Dubbink H, Atmodimedjo P, van Marion R, Krol N, Riegman P, Kros J, van den Bent M, Dinjens W. Diagnostic Detection of Allelic Losses and Imbalances by Next Generation Sequencing : 1p / 19q Co - Deletion Analysis of Gliomas . J Mol Diagnostics. 2016; 18:775-86. https://doi. org/10.1016/j.jmoldx.2016.06.002.

29. Dubbink HJ, Atmodimedjo PN, Kros JM, French PJ, Sanson M, Idbaih A, Wesseling P, Enting R, Spliet W, Tijssen C, Dinjens WN, Gorlia T, van den Bent MJ. Molecular classification of anaplastic oligodendroglioma using next-generation sequencing: a report of the prospective randomized EORTC Brain Tumor Group 26951 phase III trial . Neuro Oncol. 2016; 18:388-400. https://doi. org/10.1093/neuonc/nov182.

30. Carter J, McNulty S, Cimino P, Cottrell C, Heusel J, Vigh-Conrad K, Duncavage E. Targeted Next-Generation Sequencing in Molecular Subtyping of Lower-Grade Diffuse Gliomas: Application of the World Health Organization's 20 Central Nervous System Tumors. J Mol Diagnostics. 2017; 19:328-36. https://doi.org/10.1016/j. jmoldx.2016.10.010.

31. Ibarrola-Villava $M$, Fleitas $T$, Llorca-Cardeñosa $M J$, Mongort C, Alonso E, Navarro S, Burgues O, Vivancos A, Cejalvo JM, Perez-Fidalgo JA, Roselló S, Ribas G, Cervantes A, et al. Determination of somatic oncogenic mutations linked to target- based therapies using MassARRAY technology. Oncotarget. 2016; 7:22543-55. https://doi.org/10.18632/oncotarget.8002.

32. Fleitas T, Ibarrola-Villava M, Ribas G, Cervantes A. MassARRAY determination of somatic oncogenic mutations in solid tumors: Moving forward to personalized medicine. Cancer Treat Rev. 2016; 49:57-64. https://doi. org/10.1016/j.ctrv.2016.07.007.
33. van Puijenbroek M, Dierssen JWF, Stanssens P, van Eijk R, Cleton-Jansen AM, van Wezel T, Morreau H. Mass Spectrometry-Based Loss of Heterozygosity Analysis of Single-Nucleotide Polymorphism Loci in Paraffin Embedded Tumors Using the MassEXTEND Assay Analysis of the Protein Tyrosine Phosphatase Receptor Type. J Pathol. 2005; 7:623-30. https://doi.org/10.1016/ S1525-1578(10)60596-X.

34. Tai ALS, Mak W, Ng PKM, Chua DTT, Ng MYM, Fu L, Chu KKW, Fang Y, You QS, Chen M, Zhang M, Sham PC, Guan XY. High-throughput loss-of-heterozygosity study of chromosome $3 \mathrm{p}$ in lung cancer using single-nucleotide polymorphism markers. Cancer Res. 2006; 66:4133-8. https://doi.org/10.1158/0008-5472.CAN-05-2775.

35. Vogazianou AP, Chan R, Bäcklund LM, Pearson DM, Liu L, Langford CF, Gregory SG, Collins VP, Ichimura K. Distinct patterns of $1 p$ and $19 q$ alterations identify subtypes of human gliomas that have different prognoses. Neuro Oncol. 2010; 12:664-78. https://doi.org/10.1093/neuonc/nop075.

36. Harada S, Henderson LB, Eshleman JR, Gocke CD, Burger P, Griffin CA, Batista DAS. Genomic changes in gliomas detected using single nucleotide polymorphism array in formalin-fixed, paraffin-embedded tissue: Superior results compared with microsatellite analysis. J Mol Diagnostics. 2011; 13:541-8. https://doi.org/10.1016/j. jmoldx.2011.05.009.

37. Ambros PF, Ambros IM. Pathology and Biology Guidelines for Resectable and Unresectable Neuroblastic Tumors and Bone Marrow Examination Guidelines. Med Pediatr Oncol. 2001; 37:492-504.

38. Man R, Chen L, Zhu H. Telomeres inhibitors: a patent review (2010-2015). Expert Opin Ther Pat. 2016; 26: 679-88. https://doi.org/10.1080/13543776.2016.1181172.

39. Marian CO, Cho SK, Mcellin BM, Maher EA, Hatanpaa KJ, Madden CJ, Mickey BE, Wright WE, Shay JW, Bachoo RM. The telomerase antagonist, imetelstat, efficiently targets glioblastoma tumor-initiating cells leading to decreased proliferation and tumor growth. Clin Cancer Res. 2010; 16:154-63. https://doi.org/10.1158/1078-0432.CCR-09-2850.

40. Lebok P, Kopperschmidt V, Kluth M, Hube-Magg C, Özden C, BT, Hussein K, Mittenzwei A, Lebeau A, Witzel I, Wölber L, Mahner S, Jänicke F, et al. Partial PTEN deletion is linked to poor prognosis in breast cancer. BMC Cancer. 2015; 15:963-73. https://doi.org/10.1186/s12885-015-1770-3.

41. Kluth M, Ahrary R, Hube-Magg C, Ahmed M, Volta H, Schwemin C, Steurer S, Wittmer C, Wilczak W, Burandt E, Krech T, Adam M, Michl U, et al. Genomic deletion of chromosome $12 \mathrm{p}$ is an independent prognostic marker in prostate cancer. Oncotarget. 2015; 6:27966-79. https://doi. org/10.18632/oncotarget.4626.

42. Kawai M, Komiyama H, Hosoya M, Okubo H, Fujii T, Yokoyama N, Sato C, Ueyama T, Okuzawa A, Goto M, Kojima Y, Takahashi M, Sugimoto K, et al. Impact of chromosome $17 \mathrm{q}$ deletion in the primary lesion of colorectal cancer on liver metastasis. Oncol Lett. 2016; 12:4773-8. https://doi.org/10.3892/ol.2016.5271. 
43. MassARRAY ${ }^{\circledR}$ Typer 3.4 Software User's Guide for iPLEXTM and hME. Sequenom. 2006; 1-158.

44. Johnson MD, Vnencak-Jones CL, Toms SA, Moots PM, Weil R. Allelic Losses in Oligodendroglial and Oligodendrogliomalike Neoplasms: Analysis Using Microsatellite Repeats and Polymerase Chain Reaction. Arch Pathol Lab Med. 2003; 127:1573-9. https://doi.org/10.1043/15432165(2003)127<1573:ALIOAO>2.0.CO;2.

45. Srebotnik-Kirbis I, Limback-Stokin C. Application of brush cytology for FISH-based detection of $1 \mathrm{p} / 19 \mathrm{q}$ codeletion in oligodendroglial tumors. J Neurooncol. 2016; 129:2-9. https://doi.org/10.1007/s11060-016-2211-0.
46. Woehrer A, Sander P, Haberler C, Kern S, Maier H, Preusser M, Hartmann C, Kros JM, Hainfellner JA, Unit CC, Cancer G. FISH-based detection of $1 p 19 q$ codeletion in oligodendroglial tumors : procedures and protocols for neuropathological practice - a publication under the auspices of the Research Committee of the European Confederation of Neuropathological Societies (Euro-CNS). Clin Neuropathol. 2011; 30:47-55. https://doi. org/10.5414/NPP30047. 